\title{
How to get even with desires*
}

\author{
Luka Crnič \\ MIT
}

\begin{abstract}
The scalar particle even imposes a constraint on the likelihood of its prejacent and the alternatives on which it operates. This semantic import of even restricts its distribution: even that associates with a weak predicate in its immediate surface scope - weak even, for short - is acceptable only if it is appropriately embedded (cf. Lahiri 1998). This paper investigates the occurrence of weak even in three modal environments: under non-factive and factive desire predicates and in imperatives. The structure of the paper is the following: Section 1 describes an approach to even according to which even may move at LF (Karttunen \& Peters 1979, Lahiri 1998 and others). A prediction of the approach is that weak even is licit only if it is embedded under a non-upward-entailing operator. Section 2 presents an apparent puzzle for the approach: weak even may occur in non-negative desire statements and in imperatives, i.e. in environments that appear to be upwardentailing. Section 3 discusses two strategies for dealing with these facts: according to the first strategy, desire predicates and the imperative operator are non-monotone (e.g. Heim 1992); according to the second strategy, they are upward-entailing (e.g. von Fintel 1999) and weak even is rescued by covert exhaustification. Section 4 concludes the paper by discussing the licensing of certain negative polarity items in these environments.
\end{abstract}

Keywords: even, polarity, modality, imperatives, non-monotonicity, context dependency

\section{The meaning and distribution of even}

The primary semantic import of even is a scalar presupposition that orders the prejacent of even with respect to the alternatives on which it operates. ${ }^{1}$ There have been various proposals about the flavor and the quantificational strength of this presupposition (Karttunen \& Peters 1979, Kay 1990, Merin 1999, Herburger 2000 and many others). The choice between them is inconsequential for the discussion in

* Thanks to Gennaro Chierchia, Kai von Fintel, Danny Fox and Irene Heim for discussion as well as to the audiences at the Göttingen workshop on polarity, WCCFL 29 and SALT 21.

1 Another inference that is often assumed to be triggered by even is the additive (or existential) presupposition. Since additivity is largely tangential to the purposes of this paper, we leave it aside and refer the reader to Rullmann 1997, Guerzoni 2003 and the references cited therein.

(C2011 Luka Crnič 
this paper. For concreteness, we assume that the scalar presupposition triggered by even requires the likelihood of its propositional argument to be lower than that of a relevant alternative (Bennett 1982, Kay 1990):

$[[\text { even }]]^{g, c}(\mathrm{C}, \mathrm{p}, \mathrm{w})$ is defined only if $\exists \mathrm{q} \in \mathrm{C}\left[\mathrm{p} \triangleleft_{\mathrm{c}} \mathrm{q}\right]$.

If defined, $[[\text { even }]]^{g, c}(\mathrm{C}, \mathrm{p}, \mathrm{w})=1$ iff $\mathrm{p}(\mathrm{w})=1$

The sentence in (2a) has the structure in (2b) where even takes clausal scope at LF and associates with the focused element John. The sentence presupposes that there is an alternative that is more likely than the proposition that John made one video, while its assertive meaning is that John made one video.

(2) a. Even JOHN made one video.

b. [even $\mathrm{C}_{1}$ ] [John $\mathrm{F}$ made one video]

c. $\quad[(2 \mathrm{~b})]]^{g, c}(\mathrm{w})$ is defined only if $\exists \mathrm{q} \in\{$ that $\mathrm{x}$ made one video $\mid \mathrm{x}$ is a relevant individual \}: that John made one video $\triangleleft_{\mathrm{c}} \mathrm{q}$. If defined, $[[(2 \mathrm{~b})]]^{g, c}(\mathrm{w})=1$ iff John made one video in $\mathrm{w}$

\subsection{Scalarity, entailment and scope of even}

The scalar presupposition triggered by even is subject to the principle in (3), which follows from basic probability theory. ${ }^{2}$ The principle imposes a hard condition on the distribution of even: if even is adjoined to a clause whose alternatives entail it, it will trigger a presupposition that violates (3) and is thus unsatisfiable.

\section{Scalarity and entailment}

If a proposition $\mathrm{p}$ entails a proposition $\mathrm{q}, \mathrm{q}$ cannot be less likely than $\mathrm{p}$.

An illustration of the principle is in (4). The sentence in (4a) presupposes that it is less likely that John made one video than that he made some other number of videos (4c). Since making $n$ videos entails making one video for all $n>0$, all the alternatives in the domain of even entail its prejacent. According to (3), they cannot be more likely than it. This clashes with (4c) and explains the deviance of (4a).

a. \#John made even ONE video.

b. [even $\mathrm{C}_{1}$ ] [John made one $\mathrm{F}_{\mathrm{F}}$ video]

c. $\quad[(4 \mathrm{~b})]^{g, c}$ is defined only if $\exists \mathrm{q} \in\left\{\right.$ that John made $n$ videos $\left.\mid n \in \mathbb{N}_{>0}\right\}$ : that John made one video $\triangleleft_{\mathrm{c}} \mathrm{q}$

2 More precisely, it follows from Kolmogorov's third axiom that states that the likelihood of a union of mutually exclusive propositions equals the sum of the likelihoods of the propositions. Applied to (3), if a proposition $p$ entails a proposition $q$, it holds that the sum of the likelihoods of $p$ and $q \backslash p$ equals the likelihood of $q$. Since the likelihood of $q \backslash p$ is greater or equal to zero, it holds that the likelihood of $\mathrm{p}$ is at most as great as the likelihood of $\mathrm{q}$. 
A puzzle emerges when we look at certain embedded occurrences of even - in particular at occurrences of even in the scope of downward-entailing operators. A pertinent example is in (5a). If even were interepreted in situ in this sentence, it would trigger the same scalar presupposition as in (4); the sentence would accordingly be pragmatically deviant. Now, Karttunen \& Peters (1979) have proposed that even may covertly move out of its base position. Lahiri (1998) builds on this proposal to explain the contrast between positive and negative sentences with weak even that we see in (4) and (5): a rescue hatch is available to even in negative sentences it may covertly move above negation. That is, Lahiri assumes that the sentence in (5a) may have the LF in (5b) where there is an intervening entailments-reversing operator between the scoped even and its associate one. The presupposition of this structure is that it is less likely that John didn't make one video than, say, that John didn't make two videos (5c). Since the former proposition is logically stronger than the latter, the presupposition is compatible with (3) and may very well be correct.

a. John didn't make even ONE video.

b. [even $\mathbf{C}_{1}$ ] [not [even $\mathbf{C}_{1}$ ] [John make one ${ }_{F}$ video]]

c. $\quad\left[[(5 \mathrm{~b})]^{g, c}(\mathrm{w})\right.$ is defined only if $\exists \mathrm{q} \in\{$ that John didn't make $n$ videos $\left.n \in \mathbb{N}_{>0}\right\}$ : that John didn't make one video $\triangleleft_{\mathrm{c}} \mathrm{q}$

\subsection{Prediction}

The core ingredient of Lahiri's (1998) proposal is the assumption that even may move to avoid triggering an incorrect presupposition. He has shown that if even that associates with a weak element in its immediate surface scope moves above negation or other downward-entailing operators, the resulting structure can have a consistent and plausible interpretation since downward-entailing operators reverse entailments. However, moving even across an operator that reverses entailments is not a necessary but a sufficient condition for configurations containing weak even to comply with (3). The necessary condition is that even moves across an operator that is not upward-entailing. Besides downward-entailing operators, these include non-monotone operators. ${ }^{3,4}$

3 As pointed out by Rullmann (1997), a patent issue for this approach to even is that it allows for non-canonical movement of even, e.g. even may move out of the antecedent of a conditional. A possible way to defuse this issue has been suggested by Lahiri (2006): the scalar presupposition that accompanies sentences with even is triggered by an even-like operator (EmphAssert in Krifka 1995, E in Chierchia 2006) that is attached at the clausal level to check the relevant feature of even; even itself is truth-conditionally vacuous, it stays in situ and primarily conditions the insertion of the even-like operator. In the following we retain for perspicuity the assumption that even itself moves.

4 According to (6), weak even should be able to occur in the scope of non-monotone quantifiers. This prediction is borne out, as illustrated in (i). An investigation of this data and how it relates to the 
How to get even with desires

(6) A prediction of the movement approach to even

A sentence with a weak even is acceptable only if even is at surface structure in the scope of a non-upward-entailing operator.

\section{Weak even in desire statements and imperatives}

Weak even may occur in the scope of non-negative desire predicates and in imperatives. This is at first sight at odds with the prediction in (6).

\subsection{Non-factive desire predicates}

Weak even may occur in the scope of non-negative desire predicates like hope and would like. A few naturally occurring examples of this kind are given in (7) where we boldface the embedding desire predicate and capitalize the focused element.

(7) a. I hope to someday make even ONE video of that quality.

b. In fact, I would like to find even ONE person who hasn't had at least one paper-cut this year. People without hands do not count.

c. Everyone wants to prevent even "ONE bad incident" as BellaQuest points out. 5

Another conspicuous instance of a non-factive desire predicate that licenses weak even is wish. Two naturally occurring examples are given in (8).

a. I wish I wrote even ONE riff featured on ANY Death album.

b. This Haley chick wishes she could sing even ONE note close to Janis. ${ }^{6}$

In languages that have a dedicated scalar particle (or a collocation of particles) for weak even - e.g. auch nur in German (e.g. Guerzoni 2003) - that scalar particle is used in examples that correspond to the above data. This is illustrated in (9) where auch nur associates with $20 \%$, an expression denoting a relatively low percentage.

(9) Ich hoffe auch nur 20\% von deiner Begeisterung, die du ihm geschenkt I hope even $20 \%$ of your enthusiasm that you him given hast, bei ihm wach halten zu können.

have with him sustain to be able

poorly understood occurrences of negative polarity items in these environments is pursued elsewhere (Crnič 2011).

(i) Exactly two congressmen read even ONE book.

http://www.murdershewrites.com/tag/natalie-r-collins/, http://www.people.com/people/archive/article/0,,20141718,00.html

6 http://www.johnsoncitypress.com/News/article.php?id=91361, http://www.youtube.com/watch?v=c64 $\mathrm{DHj} 9 \mathrm{yEI}$ 
'I hope to sustain even $20 \%$ of his excitement that you caused.' 7

\subsection{Factive desire predicates}

It is well-known at least since Kadmon \& Landman (1993) that weak even may occur in the scope of non-downward-entailing factive desire predicates like glad (10a). Weak even is licensed also in the scope of other factive evaluatives (10b).

(10) a. John is glad that he read even ONE paper on this topic.

b. It's good/great/fantastic/interesting that John solved even ONE exercise.

\subsection{Imperatives}

The final class of non-negative modal environments in which weak even may occur are imperatives. Some examples of imperatives with weak even are given in (11) where even associates with the weak predicate one. Translations of these imperatives into German contain auch nur (12).

(11) a. Show me even ONE party that cares for the people.

b. Break even ONE record that I can't.

c. Give me even just ONE reason not to hurt you.

(12) Zeig mir auch nur eine Partei die sich wirklich ums Volk kümmert. show me even one party that self really for people cares

'Show me even one party that really cares for the people.' 8

These imperatives may be given natural paraphrases with the embedding predicates challenge, dare and defy (13). Interestingly, if we make the paraphrases nonperformative, weak even continues to be licensed (14).

(13) a. I challenge you to show me even ONE party that cares for the people. b. I dare you to score even ONE goal against my team.

(14) John challenged Steve to show him even ONE party that cares for the people.

7 http://www.inahallermann.de/index.php?page=rueckmeldungen ${ }_{\mathrm{v}}$ on $_{\mathrm{k}}$ lienten

8 http://www.youtube.com/all_comments?v=VWTmA5oGkeQ 
How to get even with desires

\subsection{Three challenges}

Any approach to the above data faces three challenges. First: it needs to explain why weak even in modal environments does not trigger an infelicitous scalar presupposition. Second: it needs to explain the restriction of weak even to only a subset of modal environments. Third: it needs to explain why the above sentences are accompanied by a distinct bias. We describe these three challenges in turn.

\section{Consistency of the scalar presupposition}

The occurrence of weak even in the examples above is unexpected on common assumptions about the semantics of desire predicates and the imperative operatornamely, that they are upward-entailing (e.g. Hintikka 1962, Schwager 2005). That is, they are commonly taken to license inferences along the lines of (15a): for all $n>$ 0 , that I hope to make $n$ videos entails that I hope to make one video. In accordance with the condition (3), any likelihood relation between the propositions in (15a) satisfies the condition in (15b): for all $n>0$, that I hope to make $n$ videos is at most as likely as that I hope to make one video.

a. that $\mathrm{I}$ hope to make one video $\Leftarrow$ that $\mathrm{I}$ hope to make two videos $\Leftarrow \ldots$

b. $\quad \ldots \unlhd_{c}$ that I hope to make two videos $\unlhd_{c}$ that I hope to make one video

Now, the sentence in (16a), repeated from above, may be assigned the structures in $(16 \mathrm{~b}, \mathrm{c})$. In one structure even stays in situ, while in the other it moves above the desire predicate hope.

a. I hope to someday make even ONE video of that quality.

b. [I hope [[even $\mathrm{C}_{1}$ ] [PRO ${ }_{\mathrm{I}}$ to make one $\mathrm{F}_{\mathrm{F}}$ video of that quality]]]

c. [even $\mathrm{C}_{1}$ ] [I hope $\mathrm{PRO}_{\mathrm{I}}$ to make one $\mathrm{F}$ video of that quality]

We have seen in the introduction that if even stays in situ (16b), its scalar presupposition is illicit. The same holds if even scopes above hope: the scalar presupposition triggered by even, given in (17), is at odds with the fact in (15b) - it cannot both hold that every alternative is at most as likely as the prejacent (15b) and that there is an alternative that is more likely than the prejacent (17). We are at an impasse.

[[ (17c) ] $]^{g, c}$ is defined only if $\exists \mathrm{q} \in$ \{ that I hope to make $n$ videos of that quality $\left.\mid n \in \mathbb{N}_{>0}\right\}$ : that I hope to make one video of that quality $\triangleleft_{\mathrm{c}} \mathrm{q}$ 


\section{Constrained distribution of weak even in modal environments}

Weak even is not licit in every type of modal environment. More to the point, it is not licit in epistemic and doxastic modal environments, e.g. in the scope of epistemic and doxastic attitude predicates like know, believe and think:

\#John knows/thinks that he will make even ONE video of that quality.

Furthermore, weak even is also illicit in the scope of certain non-doxastic attitude predicates. This holds for intend (19a) and the directive attitude predicates command and order (19b). As we have pointed out above, certain directive predicates differ from command and allow for a licit occurrence of weak even in their scope (20).

a. \#John intends to make even ONE video of that quality.

b. \#John commanded me to make even ONE video of that quality.

a. John challenged me to make even ONE video of that quality

b. I urge you to plant even ONE of these tubers 9

\section{Extra inference}

The occurrences of weak even in desire statements and imperatives are accompanied by a distinct bias. For example, the sentences in (21) induce the inferences that I take it to be unlikely that the addressee will find any party that cares for the people and that I take it to be unlikely that I will make one video of that quality, respectively.

a. Show me even ONE party that cares for the people.

b. I hope to someday make even ONE video of that quality.

More generally, contexts in which non-negative desire statements or imperatives with weak even are used satisfy the condition in (22). ${ }^{10}$

9 http://www.cherrymenlove.com/gardening_flowers/2011/03/story-from-a-spring-garden.html

10 The sentences in (i) appear not to trigger a low probability bias: it is very likely that Tyson will inspire a lot of kids and due to his well-known self-confidence he probably believes in it too (ia); (ib) may be addressed to a very generous philanthropist who is expected to donate a lot of money.

(i) a. Tyson, who said he hopes to inspire even ONE kid to turn his life around, has given similar speeches around the world. (http://www.lvrj.com/sports/15870627.html)

b. If you can't come, PLEASE donate even ONE DOLLAR. (http://iam.bmezine.com/ ?rebekahsxrevenge)

We suggest that even these sentences are accompanied by a low probability bias - the difference between them and the cases in the main text is that bias in (i) has the flavor of polite pretense. For example, it arguably holds that although Tyson may in fact be certain that he will inspire many kids, (ia) presents him as being excessively humble and falsely modest - i.e. low probability bias obtains 
How to get even with desires

Low probability bias

A context satisfies the low probability bias wrt a set of alternatives and an individual if the individual takes the alternatives to be unlikely to obtain

A closely related restriction has been discussed by Kadmon \& Landman (1993) with respect to the occurrence of weak even in the scope of factive desire predicates. For example, they have claimed that (23) is licit only in contexts in which we did not get better tickets than these tickets (Kadmon \& Landman 1993: 385). That is, their characterization differs from (22) in that it requires the attitude holder to believe that the alternatives have not obtained and not that they were unlikely to obtain.

I'm glad we even got THESE tickets!

However, their characterization is too strong in light of the data in (24). In contrast, the weaker characterization in (22) correctly describes the contexts in which (24) and its ilk may be used - the attitude holder only needs to believe that it was unlikely that the relevant alternatives will obtain rather than believe that they did not obtain.

(24) Just be glad that the Eastern networks could even FIND Elko, let alone have a camera there to record the speech. ${ }^{11}$

To summarize: we have presented puzzling data concerning the distribution of weak even - namely, weak even may occur in modal environments that have traditionally been classified as upward-entailing. Two further puzzles concerning the occurrence of weak even in modal environments were presented: weak even is restricted to a subset of modal environments (desire statements, imperatives) and its occurrence is accompanied by a distinct bias.

\section{Steps towards a resolution}

Two resolutions of the above puzzles are presented. The first is based on Heim's (1992) non-monotone desire semantics, while the second is based on von Fintel's (1999) monotone desire semantics. In the latter case, an additional mechanism needs to be employed to account for the felicity of weak even.

under pretense. This allows us to stick to (22) as a uniform characterization of all the data.

$11 \mathrm{http} / / / w w w . w a y i p l a y . c o m / n e w s / w h y-w o n t-n e w s-n e t w o r k s-a i r-c o m p l e t e-p o l i t i c a l-s p e e c h-r a l l i e s-$ from-start-to-finish 
Luka Crnič

\subsection{Non-monotone desire}

\section{Negation-related semantics of desire and non-monotonicity}

Heim (1992) proposes that to want $\mathrm{p}$ is, roughly, to believe that $\mathrm{p}$ is desirable (good). The belief component of this meaning is fleshed out as a doxastic accessibility function that returns for an attitude holder $\mathrm{x}$ and a world $\mathrm{w}$ a set of worlds compatible with the beliefs of $x$ in w (cf. Hintikka 1962), while the desirability component is characterized relationally: a proposition is desirable iff it is preferred to its negation, which is the case iff every world in the proposition is better than every world in the negation of the proposition. In the case at hand, these propositions are constituted by the closest belief worlds of the attitude holder in which the proposition denoted by the sentential complement of want and its negation, respectively, hold: ${ }^{12}$

$$
\begin{aligned}
& \text { If defined, [[ want }]^{g, c}(\succeq, \mathrm{p}, \mathrm{i}, \mathrm{w})=1 \text { iff } \forall \mathrm{w}^{\prime} \in \operatorname{Dox}(\mathrm{i}, \mathrm{w}): \\
& \qquad \operatorname{SIM}\left(\mathrm{w}^{\prime}, \operatorname{Dox}(\mathrm{i}, \mathrm{w}) \cap \mathrm{p}\right) \succ_{\mathrm{i}, \mathrm{w}} \operatorname{SIM}\left(\mathrm{w}^{\prime}, \operatorname{Dox}(\mathrm{i}, \mathrm{w}) \backslash \mathrm{p}\right)
\end{aligned}
$$

The presupposition triggered by want is that, roughly, its propositional argument is logically independent of the beliefs of the attitude holder. Accordingly, the sentence in (26a) presupposes that John neither believes that he will make one video of that quality nor that he won't make one video of that quality; its assertive meaning is computed in (26b): the closest belief worlds of John in which he makes one video of that quality are better than the closest belief worlds of John in which he does not.

a. John wants to make one video of that quality.

b. If defined, [[ [John [wants [PRO $\mathbf{J}$ to make one video ...] ] ] $]^{g, c}(\mathrm{w})=1$ iff $\forall w^{\prime} \in \operatorname{DOX}(i, w): \operatorname{SIM}\left(w^{\prime}, \operatorname{Dox}(i, w) \cap\right.$ that John makes one video)

$$
\succ_{\mathrm{i}, \mathrm{w}} \operatorname{SIM}(\mathrm{w}, \operatorname{DOX}(\mathrm{i}, \mathrm{w}) \cap \text { that John makes no videos })
$$

The semantics of desire predicates like hope, wish and glad is built up in a similar fashion, though some modifications might be needed with respect to the presuppositions of the predicates and the relata compared (cf. Heim 1992 for details). Furthermore, an analogous meaning can also be assigned to the imperative operator. We simplistically assume that there are two differences between it and desire predicates: first, the imperative operator does not quantify over the beliefs of an attitude holder but over the worlds in the context set, cs(c); second, the imperative operator

12 A preference relation among propositions is defined on the basis of a preference relation among worlds as in (ia) (cf. von Wright 1963: 31); the maximal similarity function is defined as in (ib) (Lewis 1973). We leave the similarity relation $\leq$ out of our representations.

(i)

$$
\begin{array}{ll}
\text { a. } & \mathrm{p} \succ_{\mathrm{i}, \mathrm{w}} \mathrm{q} \equiv_{\mathrm{df}} \forall \mathrm{w}^{\prime}, \mathrm{w}^{\prime \prime}\left(\mathrm{p}\left(\mathrm{w} \mathrm{w}^{\prime}\right)=1 \wedge \mathrm{q}\left(\mathrm{w}{ }^{\prime}\right)=1 \rightarrow \mathrm{w} \succ_{\mathrm{i}, \mathrm{w}} \mathrm{w}^{\prime \prime}\right) \\
\text { b. } & \operatorname{SIM}(\leq, \mathrm{w}, \mathrm{p}) \equiv_{\mathrm{df}} \lambda \mathrm{w}^{\prime} . \mathrm{p}\left(\mathrm{w}^{\prime}\right)=1 \wedge \forall \mathrm{w},\left(\mathrm{p}(\mathrm{w},)=1 \rightarrow \mathrm{w} \leq_{\mathrm{w}} \mathrm{w}^{\prime \prime}\right)
\end{array}
$$


How to get even with desires

triggers additional presuppositions that are responsible for its performativity (cf. Schwager 2005 for a thorough discussion of performativity of imperatives).

$$
\begin{aligned}
& \text { If defined, }[[\mathbf{I M P}]]^{g, c}(\succeq, \mathrm{p}, \mathrm{w})=1 \text { iff } \forall \mathrm{w}^{\prime} \in \operatorname{cs}(\mathrm{c}): \\
& \qquad \operatorname{SIM}\left(\mathrm{w}^{\prime}, \operatorname{cs}(\mathrm{c}) \cap \mathrm{p}\right) \succ_{\mathrm{sp}(\mathrm{c}), \mathrm{w}} \operatorname{SIM}\left(\mathrm{w}^{\prime}, \operatorname{cs}(\mathrm{c}) \backslash \mathrm{p}\right)
\end{aligned}
$$

The imperative in (28a) has the meaning in (28b): given the speaker's preferences, it is better that you show me one party that cares than that you show me no parties that care. And since the speaker is an authority, the imperative effects a command.

a. Show me one party that cares.

b. If defined, [[ IMP [you show me one party that cares] $]]^{g, c}(\mathrm{w})=1$ iff $\forall \mathrm{w}^{\prime} \in \operatorname{cs}(\mathrm{c}): \operatorname{SIM}\left(\mathrm{w}^{\prime}, \operatorname{cs}(\mathrm{c}) \cap\right.$ that you show me one party that cares) $\succ_{\mathrm{sp}(\mathrm{c}), \mathrm{w}} \operatorname{SIM}(\mathrm{w}, \operatorname{cs}(\mathrm{c}) \cap$ that you don't show me one party that cares)

The negation-related semantics described above is non-monotone. For example, it predicts the propositions denoted by (29) to be logically independent. Namely, assume that it holds (i) that I prefer making two videos of that quality to making no or exactly one video of that quality and (ii) that I prefer making no videos of that quality to making exactly one video of that quality. Clearly, (29b) is true in the scenario due to (i). (29a) is false in the scenario if there are belief worlds where I make exactly one video: the closest belief worlds to them in which I make one video of that quality are due to (ii) not better than those in which I make no videos. This demonstrates the non-upward-entailingness of desire predicates on the negation-related analysis. Their non-downward-entailingness can be demonstrated in a similar way.

a. I hope to make one video of that quality.

b. I hope to make two videos of that quality.

\section{Consistency of the scalar presupposition}

The sentence in (30a) where weak even occurs in the scope of hope may have the LF given in (30b) where even scopes above the desire predicate. The scalar presupposition that it triggers is given in (30c): there is an alternative that is more likely than that I hope to make one video of that quality.

(30) a. I hope to make even ONE video of that quality.

b. [even $\mathrm{C}_{1}$ ] [I hope [ [even $\mathrm{C}_{1}$ ] $\mathrm{PRO}_{\mathrm{I}}$ to make one $\mathrm{F}$ video ...]]

c. $\exists \mathrm{q} \in\left\{\right.$ that I hope to make $n$ videos of that quality $\left.\mid n \in \mathbb{N}_{>0}\right\}$ : that I hope to make one video of that quality $\triangleleft_{\mathrm{c}} \mathrm{q}$ 
Since it holds that none of the alternatives in the domain of scoped even entail the prejacent of even, the scalar presupposition is compatible with the condition in (3). This is in line with the prediction in (6): weak even may be acceptable in the scope of a non-upward-entailing operator - in particular, a non-monotone operator.

\section{Plausibility of the scalar presupposition}

However, the condition that there are alternatives in the domain of even that do not entail the prejacent of even is only a necessary and not yet a sufficient condition for the felicity of even. Since the scalar presupposition described in (30c) is not trivial, it is expected to be satisfied only in certain contexts. In particular, it is satisfied in contexts in which it holds (i) that if there are preferences that distinguish between a proposition that one makes a certain number of videos of that quality and a proposition that one makes another number of videos of that quality, then the proposition that describes one as making a greater number of videos of that quality will be preferred to the proposition that describes one as making a lower number of videos of that quality ${ }^{13}$ and (ii) that some relevant alternatives are preferentially distinguishable from the proposition that I make one video of that quality. In such a context, the proposition that I hope to make one video of that quality being true necessitates the distinguishable alternative, say, the proposition that I hope to make two videos of that quality to be true as well (if defined). Furthermore, it holds that the reverse relation is not true in such a context: if I hope to make two videos of that quality, it does not follow that I hope to make one video of that quality. For example, it may be that I hope to make two videos of that quality but that I prefer making no videos to exactly one video of that quality. It consequently does not hold that I hope to make one video of that quality. Thus, relative to the information state that satisfies (i) and (ii), there is an alternative that is more likely than that I hope to make one video of that quality - this is ex hypothesi the proposition that I hope to make two videos of that quality.

There are contexts that do not satisfy the two conditions discussed above: contexts in which people are indifferent between making a greater and making a lower number of videos of that quality, contexts in which they prefer making a lower to making a greater number of videos of that quality, and contexts in which it is open what people's preferences are. Since besides its desiderative component, which is not helpful in the just described contexts, there is nothing in the content of the sentence in (30a) that could be used to support the scalar presupposition in (30c), the particle is either perceived as deviant in these contexts or an appropriate preference relation is accommodated. The same considerations apply to the derivation of the plausibility

13 See e.g. Hansson 2001: 67-70 on how to define preferences among compatible propositions. 
How to get even with desires

of weak even in the scope of factive desire predicates and in imperatives. ${ }^{14}$

\section{Restricted distribution}

Weak even is illicit in the scope of doxastic attitude predicates. This is expected on the approach to attitude predicates entertained in this section: desire but not doxastic attitude predicates have a negation-related semantics; the semantics of doxastic attitude predicates is upward-entailing (Hintikka 1962). Accordingly, the scalar presupposition triggered by the sentence in (31a), given in (31c), is unsatisfiable: due to the upward-entailingness of believe it holds that for every $n>$ 0 , the proposition that I believe that John made $n$ videos of that quality entails the proposition that I believe that John made one video of that quality - thus, none of the former propositions can be more likely than the latter proposition, contra (31c).

a. \#I believe that John made even ONE video of that quality.

b. [even $\mathrm{C}_{1}$ ] [I believe John made one $F$ video of that quality]

c. $\exists \mathrm{q} \in\left\{\right.$ that I believe that John made $n$ videos of that quality $\left.\mid n \in \mathbb{N}_{>0}\right\}$ : that I believe that John made one video of that quality $\triangleleft_{\mathrm{c}} \mathrm{q}$

The infelicity of weak even under intend and command has a different source. Although both predicates arguably share the non-monotone semantics of want, which suffices for even that scopes above them to trigger a presupposition compatible with (3), this presupposition is not plausible. Unlike with hope and its kin, the desiderative component of intend and command cannot be used in tandem with the preferences in the context to support the scalar presupposition in (32c): if I intend to make one video of that quality and prefer making two videos of that quality to making one video of that quality, it does not necessarily hold that I intend to make two videos of that quality (similar reasoning applies to command). Furthermore, there is nothing else in the meaning of intend and command that would make it plausible to treat weaker intentions and commands as less likely than stronger ones.

a. \#I intend to make even ONE video of that quality.

b. \#[even $\mathrm{C}_{1}$ ] [I intend [PRO I $_{\text {I }}$ make one ${ }_{\mathrm{F}}$ video of that quality]]

c. $\exists \mathrm{q} \in\left\{\right.$ that I intend to make $n$ videos of that quality $\left.\mid n \in \mathbb{N}_{>0}\right\}$ : that I intend to make one video of that quality $\triangleleft_{\mathrm{c}} \mathrm{q}$

14 There is a prominent approach to even that assumes that even is ambiguous and that weak even spells out the item with a more restricted distribution (e.g. Rooth 1985, Rullmann 1997). Applied to the cases above, such an approach has a difficulty (i) explaining why weak even may not occur in positive episodic sentences but may occur in desire statements and imperatives and (ii) accounting for the glaring context-dependence of weak even in these environments. 
This is different with challenge. Its semantic import includes the requirement that the challenged task is difficult, e.g. in (33a) it requires it to be difficult to make one video of that quality. This information can be used in supporting an appropriate likelihood relation among the alternatives: it may very well be less likely that one is challenged to perform an easy task - making one video of that quality - rather than to perform a harder alternative task - making two or more videos of that quality.

a. I challenge you to make even ONE video of that quality.

b. [even $\mathrm{C}_{1}$ ] [I challenge you [ $\mathrm{PRO}_{\text {you }}$ to make one $F$ video ...]]

c. $\exists \mathrm{q} \in\left\{\right.$ that I challenge you to make $n$ videos of that quality $\left.\mid n \in \mathbb{N}_{>0}\right\}$ : that I challenge you to make one video of that quality $\triangleleft_{\mathrm{c}} \mathrm{q}$

\section{Extra inference}

Desire statements containing weak even occur in contexts that are biased. The bias they exhibit is described in (22), repeated below. For example, any context in which (34a) is used satisfies the condition in (34b): the attitude holder takes it to be unlikely that the alternatives to the sentential complement of hope will obtain.

Low probability bias

A context satisfies the low probability bias wrt a set of alternatives and an individual if the individual takes the alternatives to be unlikely to obtain.

a. John hopes to make even ONE video of that quality.

b. John believes it is unlikely that he will make one video of that quality.

Low probability bias emerges from the interaction of the scalar presupposition triggered by even, which is satisfied in contexts in which stronger alternatives to the sentential complement of the desire predicate are better than the proposition denoted by the sentential complement, and the link between one's desires and one's actions. We sketch the reasoning on the basis of (34): Having a desire to make a certain number of videos of that quality is linked to how the attitude holder chooses to act. Different acts result in different outcomes and the attitude holder's choice is guided by optimizing her chances of being happy with the outcomes. Now, having the desire to make one and the desire to make, say, two videos of that quality is linked to the pursuit of outcomes corresponding to making one and to making two videos of that quality, respectively. In a context in which (34a) is felicitous, the latter outcomes are more desirable to the attitude holder than the former (or at least as desirable). The pursuit of the former is thus legitimate only if the attitude holder takes the latter to be sufficiently less likely to obtain. Namely, only in this case is he optimizing her chances of being happy. 
How to get even with desires

\section{A problem for the approach}

The negation-related approach to desire and imperatives successfully explains the potential felicity of weak even in their scope. However, it faces the problem that its treatment of desire predicates and the imperative operator as non-monotone functions does not seem to be warranted in light of the data in (35) and (36), ${ }^{15}$ as has been forcefully argued by von Fintel (1999). Namely, if the semantics of desire predicates were non-monotone, the pattern in (35) should not hold and the discourse in (36) should be acceptable since the conjuncts would be independent. This is not the case.

a. John hopes to make more than five videos of that quality.

b. $\Rightarrow$ John hopes to make more than one video of that quality.

\#John wants a free flight on the Concorde but he doesn't want a flight on the Concorde.

\subsection{Monotone desire}

\section{Doubly-relative modal analysis and upward-entailingness}

The modal semantics of desire predicates is relativized to two conversational backgrounds (von Fintel 1999). The first conversational background - the modal base - delivers a set of doxastically accessible worlds of the attitude holder, while the second conversational background - the bouletic ordering source - provides the propositions that are used in ordering this set. For perspicuity, we assume that among the doxastically accessible worlds one can always find a set of worlds that are not worse with respect to the given bouletic ordering source than other doxastically accesible worlds (limit assumption); these are the desire-best worlds. ${ }^{16}$ A desire statement of the form $i$ hopes that $p$ then states that all the desire-best worlds of $i$ are such that $\mathrm{p}$ is true in them (37). As before, desire predicates presuppose that their propositional argument is independent of the attitude holder's belief state. The semantics of imperatives is identical to (37), modulo the authority presupposition (cf. Schwager 2005).

If defined, [[ hope $]]^{g, c}(\mathrm{f}, \mathrm{g}, \mathrm{p}, \mathrm{i}, \mathrm{w})=\forall \mathrm{w}^{\prime} \in \operatorname{BEST}(\cap \mathrm{f}(\mathrm{i}, \mathrm{w}), \mathrm{g}(\mathrm{i}, \mathrm{w}))\left[\mathrm{p}\left(\mathrm{w}^{\prime}\right)=1\right]$

15 Apparently convincing examples that do support the idea that desire predicates are non-monotone and that do not crucially involve context-shifting discourses are the so-called Ross's paradox examples (i) (cf. Aloni 2007 and others). We defer an investigation of them to another occasion.

(i) I hope to send this letter $\nRightarrow$ I hope to send or burn this letter

16 A world w' is not worse than a world w" with respect to an individual $i$, a world w and an ordering source $g$ iff for all $p \in g(i, w)$ : if $w^{\prime \prime} \in p$, then $w^{\prime} \in p$. The best worlds with respect to $f, g, i, w$ are $\operatorname{BEST}(\cap f(i, w), g(i, w))=\left\{w^{\prime} \mid w^{\prime} \in \cap f(i, w)\right.$ and there is no $w^{\prime \prime} \in \cap f(i, w)$ such that $w^{\prime \prime}<$ g(i,w) $\left.w^{\prime}\right\}$. 
Desire predicates and the imperative operator are clearly upward-entailing on this approach: if I hope to make two videos, then all my desire-best worlds are such that I make two videos in them; it follows that all my desire-best worlds are such that I make one video in them and, thus, that I hope to make one video.

\section{The puzzle}

If desire predicates and the imperative operator are upward-entailing, the occurrence of weak even in their scope is unexpected. Namely, a sentence like (38a) may have the two structures in (38bc) and in both structures the domain of even contains only alternatives that entail the prejacent of even, causing its scalar presupposition to be illicit. For example, the presupposition of (38c) is given in (39). It is deviant since it holds that for all $n>0$, the proposition that I hope to make $n$ videos of that quality entails the proposition that I hope to make one video of that quality and thus cannot be more likely than it.

(38) a. I hope to make even ONE video of that quality.

b. [I hope [[even $\mathrm{C}_{1}$ ] $\mathrm{PRO}_{\mathrm{I}}$ to make one $\mathrm{F}$ video of that quality]] c. [even $\mathrm{C}_{1}$ ] [I hope to make one $\mathrm{F}_{\mathrm{F}}$ video of that quality]

[[ (38c) ] ] $]^{g, c}$ is defined only if $\exists \mathrm{q} \in$ \{ that I hope to make $n$ videos of that quality $\left.\mid n \in \mathbb{N}_{>0}\right\}$ : that I hope to make one video of that quality $\triangleleft_{\mathrm{c}} \mathrm{q}$

\section{Strengthening in grammar}

Although even in (38a) moves above the desire predicate at LF as in (38c), we put forward that it quantifies in its scoped position over a different domain of alternatives than indicated in (39). Its domain is rather the one given in (40) where the alternatives are mutually exclusive: e.g. if it holds that I hope to make one video and I am okay with making exactly one video, then it is false that I hope to make, say, two videos and vice versa.

(40) $\quad$ that I hope to make $n$ videos of that quality \& I am okay with making exactly $n$ videos of that quality $\left.\mid n \in \mathbb{N}_{>0}\right\}$

This domain is obtained by inserting a covert strengthening operator ONLY that associates with one into the structure of the sentence and moving even above it:

\section{[even $\mathrm{C}_{1}$ ] [ONLY $\mathrm{C}_{0}$ ] [I hope to make one $\mathrm{F}$ video of that quality]}

A simplified meaning of ONLY is given in (42): its import is that all the alternatives

in its domain that do not entail the prejacent are false (cf. Fox 2007 for a more 
sophisticated analysis). The meaning of the sister of even in (41) is computed in (43) and is equivalent to the proposition that I hope to make one video of that quality and I am okay with making exactly one video of that quality. The alternatives in the domain of even in (41) are determined analogously and the domain has thus the form given in (40).

$$
[[\mathbf{O N L Y}]]^{g, c}(\mathrm{C}, \mathrm{p}, \mathrm{w})=1 \text { iff } \mathrm{p}(\mathrm{w})=1 \wedge \forall \mathrm{q} \in \mathrm{C}[\mathrm{p} \nsubseteq \mathrm{q} \wedge \mathrm{q}(\mathrm{w})=0]
$$

$\left[\left[\text { [ONLY } \mathbf{C}_{\mathbf{0}} \text { ] [I hope to make one } \mathbf{F}_{\mathbf{F}} \text { video of that quality] ] }\right]^{g, c}(\mathrm{w})=1\right.$ iff I hope to make one video of that quality in $\mathrm{w} \&$ for $n>1$, it is not the case that I hope to make $n$ videos of that quality in $\mathrm{w}$

\section{Consistency and plausibility of the scalar presupposition}

The scalar presupposition triggered by even in (41) is given in (44): there is an alternative that is more likely than that I hope to make one video of that quality and I am okay with making exactly one video of that quality. Since the alternatives in the domain of even are mutually exclusive, the presupposition in (44) complies with (3).

(44) $\exists \mathrm{q} \in$ \{that I hope to make $n$ videos of that quality \& I am okay with making exactly $n$ videos of that quality $\left.\mid n \in \mathbb{N}_{>0}\right\}$ : that I hope to make 1 video of that quality \& I am okay with making exactly 1 video of that quality $\triangleleft_{\mathrm{c}} \mathrm{q}$

Although due to their mutual exclusivity any likelihood relation may obtain on the alternatives described in (44), not every likelihood relation on them is plausible. More concretely, the presupposition in (44) is satisfied in contexts in which it jointly holds (i) that if there are preferences that distinguish making more videos of that quality and making fewer videos, then making more videos is preferred to making fewer and (ii) that some alternatives are preferentially distinguishable from the proposition that I make one video of that quality. Namely, given this information, the expectation is that one hopes to make a notable number of videos of that quality rather than that one hopes to make one video of that quality and is okay with just one. Thus, in such a context there is an alternative that is more likely than the prejacent.

\section{Restricted distribution and extra inference}

The infelicity of weak even in the scope of believe, intend and command is a consequence of an implausible scalar presupposition. That is, although the strengthening mechanism rescues moved even from triggering a presupposition that would clash with (3), the presupposition it does trigger is implausible. An example with a doxastic predicate is given in (45). The sentence in (45a) has the structure in (45b): even 
scopes above the doxastic predicate and the strengthening operator. The assertive meaning of the sentence is expressed in (45c).

a. \#John believes that he will make even ONE video of that quality.

b. [even $\mathrm{C}_{1}$ ] [ONLY $\mathrm{C}_{0}$ ] [John believes he will make one $\mathrm{F}_{\mathrm{F}}$ video ...]

c. John believes that he will make one video of that quality \& John believes that he might make exactly one video of that quality

The scalar presupposition of the sentence is that there is an alternative in the domain of even that is more likely than its prejacent (46). Unlike with desire predicates where their desiderative component and the relevant preferences in the context were shown to play a decisive role in making the scalar presupposition plausible, there is no component in the semantics of believe that could perform a similar function.

(46) $\exists \mathrm{q} \in$ \{that John believes that he will make $n$ videos of that quality \& John believes that he might make exactly $n$ videos of that quality $\left.\mid \mathrm{n} \in \mathbb{N}_{>0}\right\}$ : that John believes that he will make one video of that quality \& John believes that he might make exactly one video of that quality $\triangleleft_{\mathrm{c}} \mathrm{q}$

Similar considerations apply to intend and command. Namely, there is no component of the meaning of these predicates that would support the scalar presupposition triggered by weak even (see discussion in the preceding subsection). Accordingly, weak even is pragmatically deviant under intend and command. This is different for challenge that has a component that can be utilized to support the respective scalar presupposition: it requires the challenged task to be difficult. Since it naturally holds that more difficult tasks qualify as more reasonable challenges, it may very well be less likely that someone is challenged to do an easy task rather than a hard task. The extra inference is derived as in the preceding section.

\section{A problem for the approach}

The strengthening operator ONLY may apply in the absence of intensional operators. Accordingly, it could be used to rescue weak even in simple episodic sentences. For example, the sentence in (47a) could be parsed as (47b) where even takes scope above ONLY. The scalar presupposition of (47b) is given in (47c). It complies with (3) and may very well be true - it may be the case that it is less likely that John read exactly one book than, say, that he read exactly two books. That is, the presupposition in $(47 \mathrm{c})$ is satisfied in appropriate contexts. However, the sentence in (47a) is judged as deviant even in such contexts. This is unexpected.

a. \#John read even ONE book.

b. [even $\mathrm{C}_{1}$ ] [ONLY $\mathrm{C}_{0}$ ] [ John read one $\mathrm{F}$ book] 
How to get even with desires

c. $\quad\left[[(47 \mathrm{a})]^{g, c}\right.$ is defined only if $\exists \mathrm{q} \in$ \{ that John read exactly $n$ books $\left.\mathbb{N}_{>0}\right\}$ : that John read exactly one book $\triangleleft_{\mathrm{c}} \mathrm{q}$

\section{Conclusion}

Weak even is in appropriate contexts felicitous in non-negative desire statements and in imperatives. If we assume that even may move at LF, this is expected on the negation-related approach to desire and imperatives. Namely, since the approach assigns the respective operators a non-monotone semantics, movement of even above them allows even to trigger a presupposition that is correct in appropriate contexts. The main problem for the negation-related approach is that non-negative desire predicates and the imperative operator appear to be upward-entailing rather than non-monotone. On the more standard modal approach to desire and imperatives, the occurrence of weak even is at first unexpected in these environments - namely, according to the approach they are upward-entailing and weak even should not be able to occur in upward-entailing environments. We dealt with this puzzle by assuming that a strengthening mechanism may apply in the scope of moved even that allows it to trigger a correct presupposition. The main problem for the approach is restricting the application of this rescuing mechanism. A further investigation into both of the above-mentioned problems is mandated.

We conclude the paper by looking at the occurrences of stressed any and ever in desire statements and imperatives (48). These are unexpected on the characterization of the licensing conditions of negative polarity items (NPIs) in (49) (von Fintel 1999). Namely, desire predicates and the imperative operator are either non-monotone or upward-entailing - they are not (Strawson) downward-entailing (DE).

a. I am glad that ANYONE likes me. (Kadmon \& Landman 1993)

b. Find me a politician that EVER cared for us AT ALL.

c. He wished ANYONE AT ALL would look at him with that same love and sweetness.

NPI licensing condition

NPIs are only grammatical if they are in the scope of a Strawson DE operator.

A possible response to the data in (48) is to redefine the NPI licensing condition, e.g. so that it requires NPIs to occur under non-upward-entailing operators (cf. Progovac 1994: 279). However, any such response leaves a crucial property of the NPIs in (48) unexplained: their context-dependence. For example, Kadmon \& Landman (1993: 388) point out that (48a) is only felicitous in contexts in which the attitude holder has a preference for a certain subset of people in the domain of anyone to like 
him. In this respect, the sentences in (48) closely resemble desire statements and imperatives with weak even that we have discussed in this paper. This resemblance suggests that a more fruitful way of dealing with (48) might be to assume that their distribution is governed by a covert even (Krifka 1995). More precisely, we may assume that stressed any and ever are existential quantifiers that come with a covert even; their alternatives are existential quantifiers that differ from any and ever only in that their domains are subsets of the domains of any and ever (Krifka 1995, Chierchia 2010). This effectively reduces the configurations with stressed any and ever to those with weak even discussed above: even associates with an element that is entailed by all of its alternatives. The derivation of the correctness of the scalar presuppositions triggered by the covert even in (48) may thus proceed along the lines described in section 3. Since stressed any and ever are 'licensed' if the covert even that associates with them triggers a correct scalar presupposition, their felicity and context-dependence in (48) is explained.

\section{References}

Aloni, Maria. 2007. Free choice, modals, and imperatives. Natural Language Semantics 15(1). 65-94.

Bennett, Jonathan. 1982. Even if. Linguistics and Philosophy 5(3). 403-418.

Chierchia, Gennaro. 2006. Broaden your views. Implicatures of domain widening and the 'logicality' of language. Linguistic Inquiry 37(4). 535-590.

Chierchia, Gennaro. 2010. Meaning as an inferential system: Polarity and free choice phenomena. Harvard University.

Crnič, Luka. 2011. Getting even: MIT dissertation.

von Fintel, Kai. 1999. NPI licensing, Strawson entailment, and context dependency. Journal of Semantics 16(2). 97-148.

Fox, Danny. 2007. Free choice and the theory of scalar implicatures. In Uli Sauerland \& Penka Stateva (eds.), Presupposition and Implicature in Compositional Semantics, 71-120. Palgrave Macmillan.

Guerzoni, Elena. 2003. Why even ask? On the pragmatics of questions and the semantics of answers: MIT dissertation.

Hansson, Sven Ove. 2001. The Structure of Values and Norms. Cambridge University Press.

Heim, Irene. 1992. Presupposition projection and the semantics of attitude verbs. Journal of Semantics 9(3). 183.

Herburger, Elena. 2000. What counts: Focus and quantification, vol. 36. The MIT Press.

Hintikka, Jaakko. 1962. Knowledge and belief: an introduction to the logic of the two notions. Cornell University Press. 
How to get even with desires

Kadmon, Nirit \& Fred Landman. 1993. Any. Linguistics and Philosophy 16(4). 353-422.

Karttunen, Lauri \& Stanley Peters. 1979. Conventional implicature. In C.-K. Oh \& D. A. Dinneen (eds.), Syntax and semantics, vol. 11, 1-56. Academic Press.

Kay, Paul. 1990. Even. Linguistics and Philosophy 13(1). 59-111.

Krifka, Manfred. 1995. The Semantics and Pragmatics of Weak and Strong Polarity Items. Linguistic Analysis 25. 209-257.

Lahiri, Utpal. 1998. Focus and Negative Polarity in Hindi. Natural Language Semantics 6. 57-123.

Lahiri, Utpal. 2006. Scope, presuppositions and dimensions of meaning: Some observations on scalar additive particles in English, Hindi and Spanish. Handout from Sinn und Bedueutung 11, Universitat Pompeu-Fabra, Barcelona.

Lewis, David. 1973. Counterfactuals. Wiley-Blackwell.

Merin, Arthur. 1999. Information, relevance, and social decisionmaking: some principles and results of decision-theoretic semantics. In Larry Moss, Jonathan Ginzburg \& Maarten de Rijke (eds.), Logic, Language and Computation, vol. 2, CSLI Publications.

Progovac, Ljiljana. 1994. Negative and Positive Polarity: A Binding Approach. Cambridge University Press.

Rooth, Mats. 1985. Association with focus: University of Massachusetts, Amherst dissertation.

Rullmann, Hotze. 1997. Even, polarity, and scope. Papers in Experimental and Theoretical Linguistics 4. 40-64.

Schwager, Magdalena. 2005. Interpreting imperatives: University of Frankfurt/Main dissertation dissertation.

von Wright, Georg H. 1963. The Logic of Preference. University of Edinburgh Press.

Luka Crnič

77 Massachusetts Avenue

02139 Cambridge, MA, USA

crnic@mit.edu 